\title{
Resident Participation in International Surgical Missions is Predictive of Future Volunteerism in Practice
}

\author{
Shruti Chudasama Tannan ${ }^{1}$, Thomas J Gampper ${ }^{2}$ \\ ${ }^{1}$ The Hand Center of San Antonio, San Antonio, TX; ${ }^{2}$ Department of Plastic and Maxillofacial Surgery, University of Virginia, \\ Charlottesville, VA, USA
}

Background Interest in global health and international mission trips among medical student and resident trainees is growing rapidly. How these electives and international mission experiences affect future practice is still being elucidated. No study has identified if participation in international surgical missions during residency is a predictor of participation in international surgical missions in practice after training completion.

Methods All trainees of our plastic surgery residency program from 1990 to 2011, during the implementation of optional annual international surgical missions, were surveyed to determine if the graduate had gone on a mission as a resident and as a plastic surgeon. Data were compared between graduates who participated in missions as residents and graduates who did not, from 1990 to 2011 and 1990 to 2007.

Results Of Plastic Surgery graduates from 1990 to 2011 who participated in international missions as residents, $60 \%$ participated in missions when in practice, versus $5.9 \%$ of graduates participating in missions in practice but not residency $(P<0.0001)$. When excluding last 5 years, graduates participating in international missions in practice after doing so as residents increases to $85.7 \%$, versus $7.41 \%$ who participate in practice but not residency $\mathrm{P}<0.002$.

Conclusions Results reveal plastic surgeons who participate in international surgical missions as residents participate in international surgical missions in practice at higher rates than graduates who did not participate in missions during residency. International missions have significant intrinsic value both to trainee and international communities served, and this opportunity should be readily and easily accessible to all plastic surgery residents nationwide.

Keywords Official medical missions / Volunteers / World health

\section{Correspondence:}

Shruti Chudasama Tannan

The Hand Center of San Antonio, 21

Spurs Lane, San Antonio, TX 78240, USA

Tel: +1-434-924-0000

Fax: +1-434-924-1333

E-mail: shruti.tannan@gmail.com

No potential conflict of interest relevant to this article was reported.

\section{INTRODUCTION}

The literature is replete with data demonstrating a recent increase in interest in global health and international mission trips among medical students and resident trainees in many specialties [1-4]. Multiple institutions regularly participate in organized international mission trips or allow students and residents to attend newly created international health electives as a response

Copyright $($ C 2015 The Korean Society of Plastic and Reconstructive Surgeons

This is an Open Access article distributed under the terms of the Creative Commons Attribution Non-Commercial License (http://creativecommons.org/

licenses/by-nc/3.0/) which permits unrestricted non-commercial use, distribution, and reproduction in any medium, provided the original work is properly cited. I www.e-aps.org 
to this increased interest in global awareness and public health [2-4]. Increased awareness and interest have translated into improved education, as both the electives and international missions fulfill the six core competencies of the Accreditation Council for Graduate Medical Education and the Residency Review Committee [4-7]. The multiple benefits to the trainees and the communities served have been previously reported [3-5,7-16], but controversy still persists [17]. Specifically, critics of international surgical missions have pointed out the perils that result from visiting surgeons performing complex procedures or procedures they are unqualified to perform, and then leaving the patients with local physicians to manage pursuant complications [17].

Subsequently, consensus guidelines have been published to ensure ethical standards and surgical safety on volunteer missions $[18,19]$. Other authors have also published recommendations detailing how to create an organization to coordinate all aspects of an international mission trip and highlighting the importance of communication and integration with local surgeons as an fundamental component to a successful international surgical mission $[12,13,20]$.

Overall, $27 \%$ of all plastic surgeons practicing in the United States participate in international surgical missions [21]. No study to date has identified what percentage of plastic surgeons who participate in international surgical missions during residency ultimately participate in international surgical missions in practice after completing their training. This study reveals that plastic surgeons who participate in international surgical missions as residents go on to participate in international surgical missions once in practice at significantly higher rates than graduates who did not participate in these missions during residency do.

The hypothesis of this study was that participation in international surgical missions during residency would result in increased participation in future international surgical missions in practice after training.

\section{METHODS}

Since 1990, plastic surgery residents at the University of Virginia have had the option of participating in international surgical missions during their residency training. The majority of these missions were to a rural area of India (Jharkhand), but have also included the Dominican Republic and Haiti. Missions were carried out under the leadership of two faculty members of the Department of Plastic Surgery: the professor who instituted the program lead missions in 1990 and 1991, and after his departure, the senior author has lead missions since 1991. The plastic surgical procedures performed were primarily cleft lip and sec- ondary burn cases. A smaller percentage included other congenital (nevi, syndactyly, and microtia) and traumatic cases. The length of each mission ranged from seven to 11 days and the missions were carried out in rudimentary settings, with nursing and anesthesiology care provided as part of the surgical team.

All trainees of this residency program since annual international surgical missions were implemented were surveyed to determine if the graduate had gone on an international mission as a resident and/or as a practicing plastic surgeon. There were a total of 46 graduates in the 21-year period from 1990 to 2011, and they were contacted by both phone and email.

Graduates were then separated into four groups. Group 1 consisted of all survey responders since 1990 that participated in international missions while in practice, but not during residency. Group 2 was comprised of graduates who went on international missions as residents and in practice, once their training was completed. Group 3 consisted of survey responders since 1990 (with the exclusion of graduates from the last five years) that also participated in international missions in practice but not during residency. This separation of the groups based on the last five years was performed to account for the many challenges that face new graduates immediately after completing residency that might preclude an international mission, including fellowship training, board certification, and setting up a new practice. Group 4 was comprised of graduates who went on international missions as residents and in practice after their training was completed, with the exception of graduates from the past five years.

A statistical database was created using Microsoft Excel. Data were analyzed using the chi-squared test with the Yates Continuity Correction. Statistical significance was set at the P-value of 0.05 .

\section{RESULTS}

Of the 46 total graduates from the plastic surgery program since the implementation of the optional international surgical missions program in 1990 to date, 44 graduates responded to the survey, for an overall response rate of $95.7 \%$. This response included 34 of the 36 former trainees who graduated between 1990 and 2007, with a response rate of $94.4 \%$. There were two graduates in group 1, consisting of all survey responders since 1990 that participated in international missions while in practice but not as residents. Group 2 consisted of six graduates since 1990 who went on international missions as residents and after their training was completed. There were two graduates in group 3, including all survey responders from 1990 to 2007 that participated in international missions in practice but not as residents. Group 4 was composed of six residents from 1990 to 2007 who 
Table 1. Survey results

\begin{tabular}{|ll}
\hline Group & \multicolumn{1}{c}{ Survey results } \\
\hline Group 1 & Percentage of graduates from 1990-2011 participating in missions in practice but not as trainees \\
Group 2 & Percentage of graduates from 1990-2011 participating in missions in practice and as trainees \\
Group 3 & Percentage of graduates from 1990-2007 participating in missions in practice but not as trainees \\
Group 4 & Percentage of graduates from 1990-2007 participating in missions in practice and as trainees \\
\hline $\begin{array}{l}\text { The difference in graduates participating in missions in training and subsequently in practice is statistically significant when compared to the graduates who have participated } \\
\text { in missions in practice but did not do so during residency. That difference is greater when more established graduates are examined (graduates before 2007). }\end{array}$ \\
\hline
\end{tabular}

\section{Fig. 1. Graduates since 1990}

Of the plastic surgery graduates since 1990 who participated in international missions as residents, 60\% also participated in one or more missions once in practice. This is in contrast to the $5.88 \%$ of graduates since 1990 who did not participate as residents but ultimately did so while in practice.

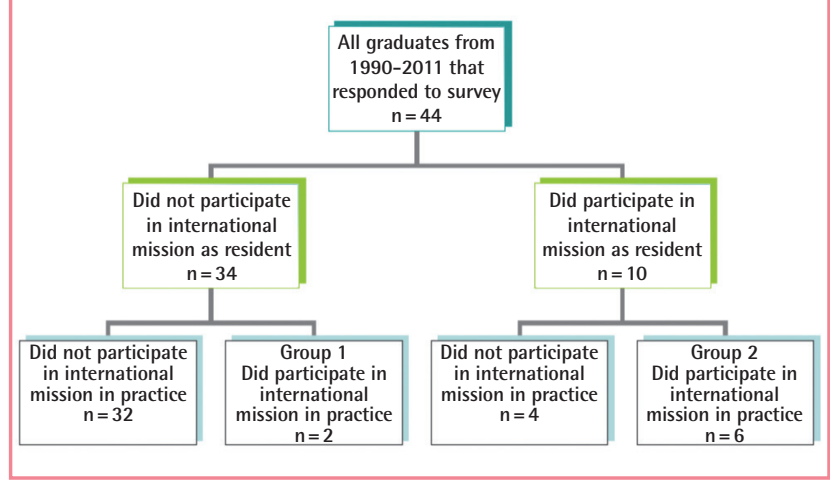

went on international missions both as residents and after their training was completed.

Of the plastic surgery graduates since 1990 who participated in international missions as residents, $60 \%$ also participated in one or more missions once in practice. When we excluded the graduates from the last 5 years, the percentage of graduates participating in international missions in practice after doing so as residents increased to $85.7 \%$. This finding is in contrast to the $5.88 \%$ of graduates since 1990 who did not participate as residents but ultimately did so while in practice. Likewise, $7.41 \%$ of graduates who did not participate in missions as residents, excluding those who graduated during the last five years, later did so while in practice (Figs. 1, 2).

The percentage of graduates since 1990 who participated in missions both in practice and residency (group 2, 60.0\%) was significantly different from the percentage of those who did so in practice but not as trainees (group 1, 5.88\%; $\mathrm{P}<0.001$ ). Moreover, the percentage of graduates from 1990 to 2007 who participated in missions both in practice and as trainees (group 4, 85.7\%) was significantly different from the percentage of graduates that participated only in practice (group 3, 7.41\%; $\mathrm{P}<0.002$ ) (Table 1).

\section{Fig. 2. Graduates from 1990 to 2007}

When excluding the last five years of graduates, those participating in international missions in practice (after doing so as residents) increased to $85.7 \%$. In contrast, $7.41 \%$ of graduates who did not participate in missions as residents (excluding the last five years) later did participate in missions while in practice.

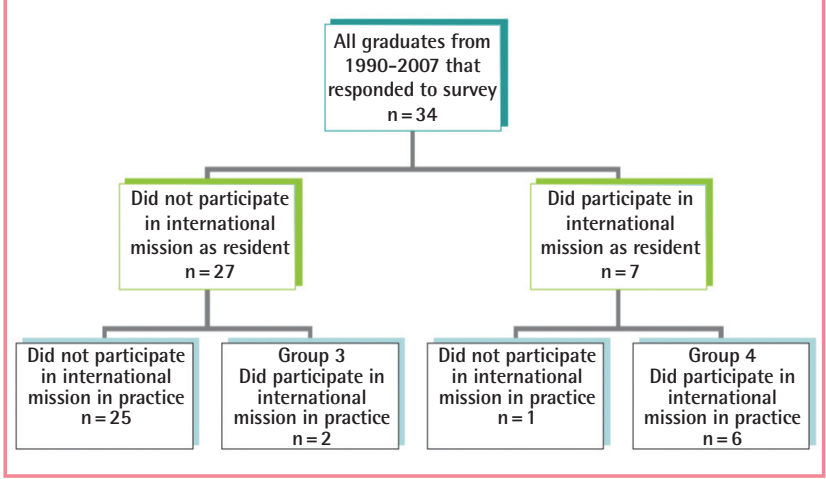

\section{DISCUSSION}

The many benefits of international health electives or missions to both residents and medical students have been previously and extensively studied and described [3-5,7-16]. These benefits include improved cultural competency and sensitivity, increased career interest in public health and volunteerism in the surgeons' own communities, and improved clinical and surgical skills [3-5,7-16]. Additional benefits of resident participation in international surgical missions include an increased global awareness of the severity of disease, increased and diverse opportunities for collaborative research projects, and improved infrastructure for future surgical collaboration in the international communities that are visited by the surgeons [8]. It has been reported that international mission trips reawaken the humanity in residents, reminding them why they chose medicine [7]. This reminder is especially important for residents training in today's era of defensive medicine, during which time most of the residents' mentors have been subjected to the personal and professional stress of a lawsuit [13]. The subsequent professional disillusionment experienced by academic surgeons nationwide is transferred to the residents, and international surgical mission 
trips provide an excellent antidote to that sentiment [16].

Recognizing the value of the many benefits of international surgical missions, as well as the proven fulfillment of all six Accreditation Council for Graduate Medical Education core competencies, many residency programs are moving toward creating international electives to encourage regular participation in international surgical missions [4-7]. Reports of interest in international missions and the success of electives or regular trips in the literature are increasing $[2-5,7,12-14,16]$. Our results prove that the inherent commitment to caring for underserved and vulnerable populations cultivated during an international surgical mission trip in residency actually translates into continued dedication to these populations in postgraduate physician practice.

Based on our study, an international surgical mission trip as a resident will very likely not be the last surgical mission that physician makes. In the first sixteen years since inception, $85.7 \%$ of the graduates of our program who participated in international surgical missions as residents became involved with similar missions after completing their training. Including the last five years of graduates decreases that percentage to $60 \%$, reflecting the many pressures on the recent graduate including fellowship training, board certification, and building a new practice, which may temporarily preclude subsequent missions. Both values were significantly greater than the percentage of former trainees who went on to participate in international surgical missions in practice but who had not done so during their residency. Our results demonstrate that participation in international surgical missions during residency is associated with a significant likelihood of continuation after graduation, when compared to residents who did not have this experience

Our findings are consistent with the only other published data from any surgical subspecialty. Disston et al. [2] found that $19 \%$ of former orthopedic surgery residents who participated in a month-long international orthopedic surgery elective rotation went on international surgical missions after residency, compared to the $6 \%$ of graduates who did not participate in the international rotation in residency but ultimately did participate in international surgical missions in practice. Thus, the benefits to both the physicians and the international communities served are maintained after residency. If those residents were followed for a longer period after residency (the survey included graduates immediately after completing residency up to 8 years after completion) [2], the percentage of residents participating in missions would very likely increase, as our data over periods of 16 years and 21 years suggest.

Authors from varying surgical subspecialties, ranging from orthopedic surgery to oral maxillofacial surgery and plastic surgery, have previously argued for incorporating international surgical missions as regular rotations in residency training programs $[2$, $4,5,8,13,16]$. International missions have significant intrinsic value both to the trainee and the international communities served, and this opportunity should be readily and easily accessible to all plastic surgery residents nationwide. Residents should be encouraged by their programs to take part in international surgical missions for the proven educational, personal, and professional benefits afforded by such trips. Our results demonstrate that resident participation in international surgical missions during training significantly increases such activity during their years of practice. The global impact of regular implementation of international surgical missions during residency training nationwide would be immense, and could reduce health disparities if executed appropriately according to previously published guidelines $[7,10,18,19,22]$. Consistent opportunities for international surgical missions should be strongly considered by program directors in plastic surgery as well as other surgical subspecialties in the developed world because of the many benefits of such programs both during and after training.

\section{REFERENCES}

1. Association of American Medical Colleges. 2010 GQmedical school graduation questionnaire, all schools summary report [Internet]. Washington, DC: Association of American Medical Colleges; c2012 [cited 2012 Apr 11]. Available from: https://www.aamc.org/download/140716/data/2010_ gq_all_schools.pdf.

2. Disston AR, Martinez-Diaz GJ, Raju S, et al. The international orthopaedic health elective at the University of California at San Francisco: the eight-year experience. J Bone Joint Surg Am 2009;91:2999-3004.

3. Thompson MJ, Huntington MK, Hunt DD, et al. Educational effects of international health electives on U.S. and Canadian medical students and residents: a literature review. Acad Med 2003;78:342-7.

4. Aziz SR, Ziccardi VB, Chuang SK. Survey of residents who have participated in humanitarian medical missions. J Oral Maxillofac Surg 2012;70:e147-57.

5. Campbell A, Sherman R, Magee WP. The role of humanitarian missions in modern surgical training. Plast Reconstr Surg 2010;126:295-302.

6. Campbell A, Sullivan M, Sherman R, et al. The medical mission and modern cultural competency training. J Am Coll Surg 2011;212:124-9.

7. Ozgediz D, Wang J, Jayaraman S, et al. Surgical training and global health: initial results of a 5-year partnership with a surgical training program in a low-income country. Arch Surg 
2008; 143:860-5.

8. Patel A, Sinha I, McRae M, et al. The role of academic plastic surgery institutions in addressing the global burden of surgical disease. Plast Reconstr Surg 2011;127:1019-20.

9. Patel A, Persing JA. 990 form: a taxing burden for cleft organizations. Plast Reconstr Surg 2009; 124:436e-437e.

10. Bermudez LE. Operation Smile: plastic surgery with few resources. Lancet 2000;356:\$45.

11. Bermudez LE. Humanitarian missions in the third world. Plast Reconstr Surg 2004;114:1687-9.

12. Figus A, Fioramonti P, Morselli P, et al. Interplast Italy: a 20year plastic and reconstructive surgery humanitarian experience in developing countries. Plast Reconstr Surg 2009;124: $1340-8$.

13. Rovinsky D, Brown HP, Coughlin RR, et al. Overseas volunteerism in orthopaedic education. J Bone Joint Surg Am 2000; 82:433-6.

14. Noland SS, Lee GK. Plastic surgery residency graduate outcomes: a 43-year experience at a single institution and the first "integrated" training program in the United States. Ann Plast Surg 2012;68:404-9.

15. Huang AH, Rhodes WR. Hospital-based plastic surgery volunteerism: a resident's international experience. Ann Plast
Surg 2012;68:396-400.

16. Haskell A, Rovinsky D, Brown HK, et al. The University of California at San Francisco international orthopaedic elective. Clin Orthop Rel Res 2002;(396):12-8.

17. Dupuis CC. Humanitarian missions in the third world: a polite dissent. Plast Reconstr Surg 2004;113:433-5.

18. Schneider WJ, Politis GD, Gosain AK, et al. Volunteers in plastic surgery guidelines for providing surgical care for children in the less developed world. Plast Reconstr Surg 2011; 127:2477-86

19. Schneider WJ, Migliori MR, Gosain AK, et al. Volunteers in plastic surgery guidelines for providing surgical care for children in the less developed world: part II. Ethical Considerations. Plast Reconstr Surg 2011;128:216e-222e.

20. Abenavoli FM. Operation Smile humanitarian missions. Plast Reconstr Surg 2005;115:356-7.

21. Medscape. Do plastic surgeons have more (or less) fun? a lifestyle report [Internet]. New York, NY: WebMD; c2012 [cited 2012 Mar 23]. Available from: http://www.medscape. com/features/slideshow/lifestyle/2012/plastic-surgery.

22. Shaywitz DA, Ausiello DA. Global health: a chance for western physicians to give-and receive. Am J Med 2002;113:354-7. 